\title{
Experimental investigation on micromachining of epoxy/graphene nano platelet nanocomposites
}

\author{
Guoyu Fu ${ }^{1} \cdot$ Dehong Huo ${ }^{1} \cdot$ Islam Shyha ${ }^{2} \cdot$ Ketan Pancholi ${ }^{3} \cdot$ Bandar Alzahrani $^{4}$
}

Received: 15 May 2019 / Accepted: 9 March 2020 / Published online: 10 April 2020

(C) The Author(s) 2020

\begin{abstract}
This paper investigates the effect of graphene nano platelet (GNP) content (\%weight fraction) on the machinability of epoxy/ GNP nanocomposites. The machinability of nanocomposites with varying loadings of GNP content was evaluated experimentally through the characterisation of cutting forces, surface morphology, chip morphology and tool wear. The minimum chip thickness phenomena of epoxy/GNP occurred at feed per tooth (FPT) between 0.2 and $0.4 \mu \mathrm{m}$. In order to achieve to better surface quality, the FPT should be over $0.4 \mu \mathrm{m}$. Epoxy/GNP with $1.0 \mathrm{wt} \%$ nanocomposite has produced the highest cutting force of a feed rate of $\sim 3 \mathrm{~N}$ at $12 \mu \mathrm{m} / \mathrm{rev}$. Epoxy/GNP nanocomposites exhibit the different cracking tendencies compared with plain epoxy, and the tool wear for GNP/epoxy nanocomposites is very small compared with metal nanocomposites. There is no significant difference in slot width accuracy between different types of tools, such as uncoated tool, diamond-like carbon-coated and diamond-coated tools.
\end{abstract}

Keywords Micromachining $\cdot$ Micro milling $\cdot$ Nanocomposites $\cdot$ Graphene nano platelet (GNP)

\section{Introduction}

Graphene nano platelets (GNP) consists of thin graphite sheets with a thickness below $100 \mathrm{~nm}$ and exhibits extraordinary mechanical, electrical and thermal properties [1,2]. It can reach the values of Young's modulus of $1000 \mathrm{GPa}$, fracture strength of $125 \mathrm{GPa}$, thermal conductivity of $5000 \mathrm{Wm}^{-1} \mathrm{~K}^{-1}$ and charge carrier mobility of $200,000 \mathrm{~cm}^{2} \mathrm{~V}^{-1} \mathrm{~s}^{-1}$ [3, 4]. Based on such superior properties, applications of GNP have attracted great attention [5-7]. Therefore, GNP has been experimentally added to various kinds of polymers such as epoxy, poly (styrene), poly

Dehong Huo

dehong.huo@newcastle.ac.uk

1 School of Engineering, Newcastle University, Newcastle upon Tyne NE1 7RU, UK

2 Department of Mechanical and Construction Engineering, Northumbria University at Newcastle, Newcastle upon Tyne NE1 8ST, UK

3 School of Engineering, Robert Gordon University, Aberdeen AB10 7AQ, UK

4 Department of Mechanical Engineering, College of Engineering in Al-Kharj, Prince Sattam bin Abdulaziz University, Al-Kharj 11942, Saudi Arabia (acrylonitrile) and poly (methyl methacrylate) matrices [7, 8]. For example, PMMA/GNP $0.1 \mathrm{wt} \%$ nanocomposites can obtain a 33\% improvement in Young's modulus compared with plain PMMA [7], and Epoxy/GNP $0.1 \mathrm{wt} \%$ nanocomposites can obtain a $31 \%$ Young's modulus greater compared with that of plain epoxy [8]. The results of other mechanical tests such as critical buckling load [9] and friction [10] tests have also demonstrated that the addition of GNP lead to considerable improvements in mechanical properties. Hence, GNP is an effective nanofiller to improve matrix material properties. And, the combination of GNP and epoxy has received more and more attention than other polymer/GNP nanocomposites [4]. This may be due to two reasons. First is that epoxy has a wide range of applications, and so the improvement of its mechanical properties can bring huge economic benefits. The second is that GNP can significantly improve the mechanical properties of epoxy compared with other polymer materials. Rafiee et al. [9] reported that epoxy/GNP $0.125 \mathrm{wt} \%$ exhibited increased fracture toughness by $65 \%$ and the fracture energy increased by $115 \%$ compared with plain epoxy. Rafiee et al. [10] also found that epoxy/GNP $0.125 \mathrm{wt} \%$ had a 25 -fold reduced crack propagation rate compared with plain epoxy under similar fatigue conditions. Gojny et al. [11] have demonstrated that epoxy/GNP $0.1 \mathrm{wt} \%$ can significantly increase the critical buckling load by up to $52 \%$ compared with plain epoxy. In 
Fig. 1 a Scanning electron microscopy (SEM) image of GNP, reproduced from [32]. b GNP clusters, reproduced from [33] c Transmission electron microscopy (TEM) image of layered GNP in the matrix material, reproduced from [34]
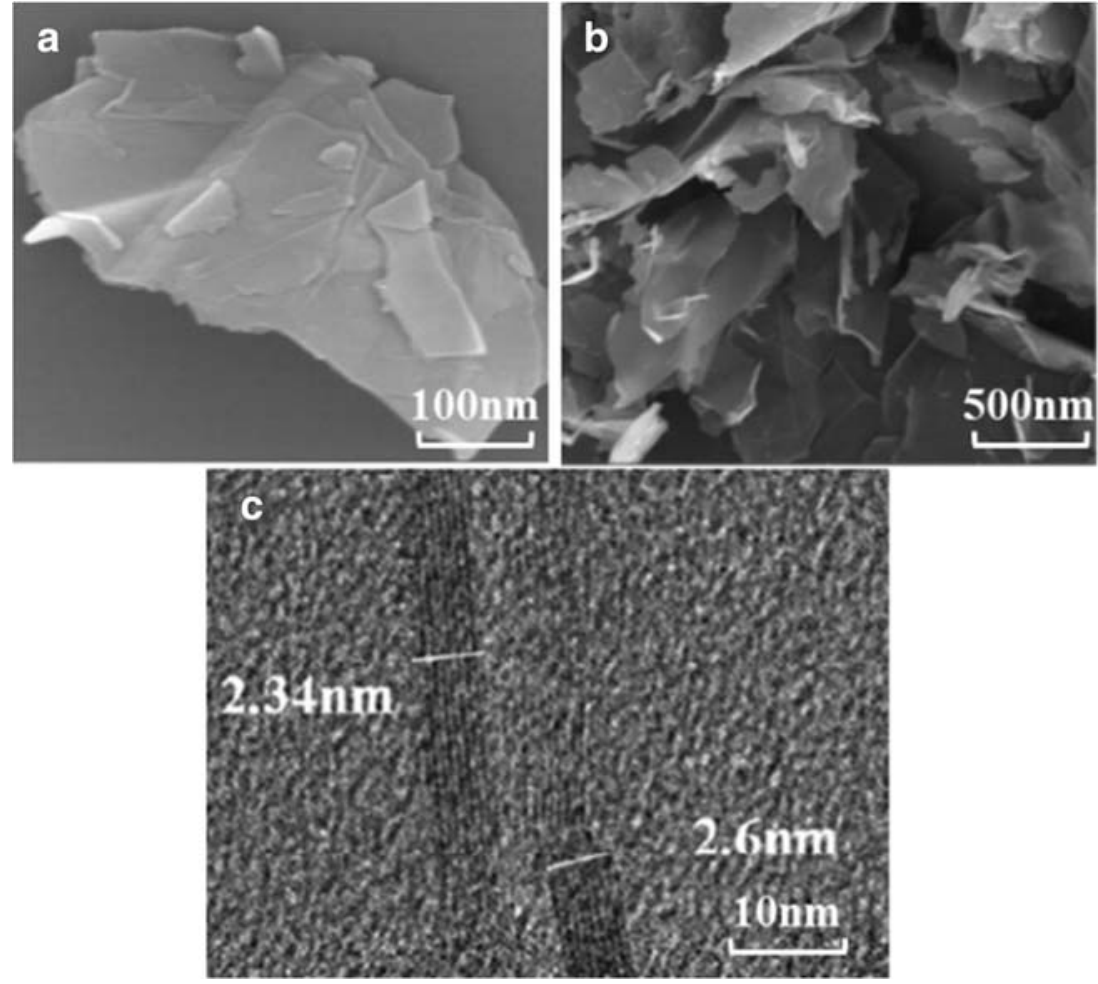

summary, GNP is an efficient nanofiller which can improve properties of epoxy, and most studies of GNP nanocomposites have reported below $1.0 \mathrm{wt} \%$. Compared with nano carbon fibre-reinforced polymer composites, GNP nanocomposites are an isotropic material [12]. Moreover, the GNP nanofiller is a highly efficient filler. Adding a small amount of GNP can
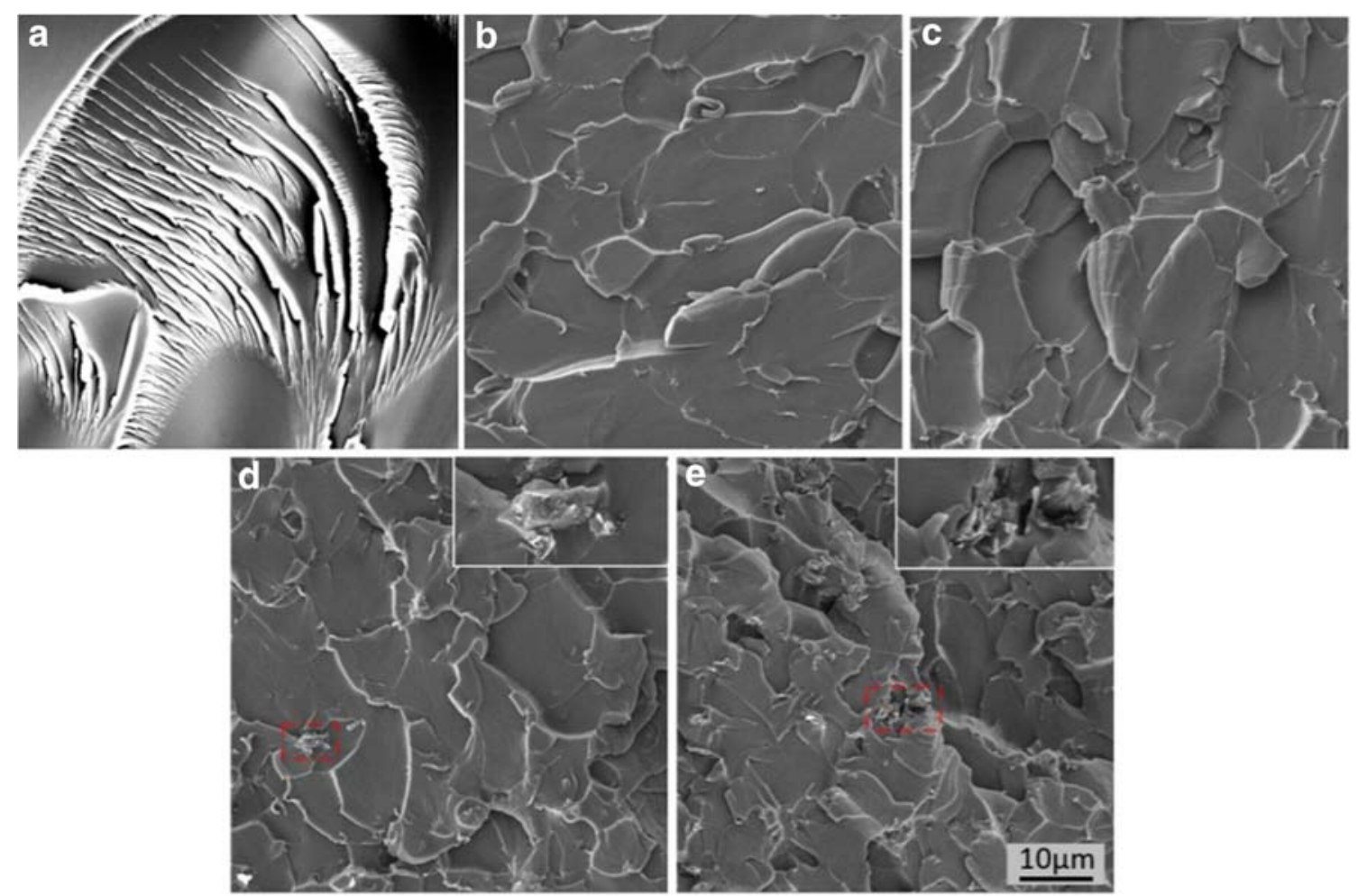

Fig. 2 SEM images of fracture surfaces. a Plain epoxy. b Epoxy/GNP $0.1 \mathrm{wt} \%$. c Epoxy/GNP 0.3 wt $\%$. d Epoxy/GNP 0.5 wt\%. e Epoxy/GNP 1.0 wt\%, reproduced from [32] 
Fig. 3 Epoxy/GNP nanocomposites samples for micro milling experiments

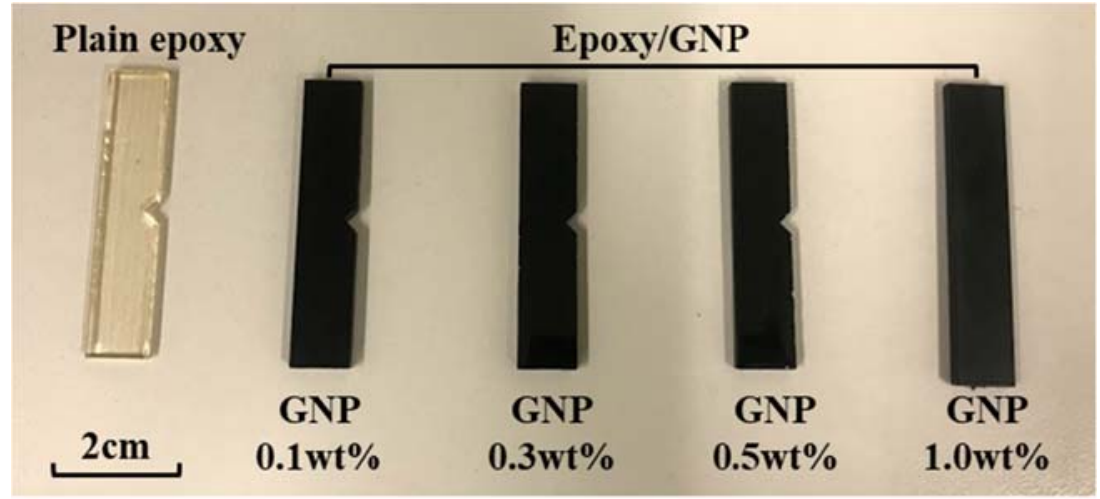

enhance the mechanical properties of the material as much as a large amount of nano carbon fibres [13].

Epoxy/GNP has a wide range of applications in the electronics industry, including for electrodes [14], capacitors [15], electronics [16] and semiconductors [17]. Hence, epoxy/GNP is usually used to make near-net shape in the electronics industry. Electronic products have high surface and dimensional accuracy as well as small features such as micro-holes and micro-slots. They must be produced using machining processes. Therefore, it is important to understand the machinability of epoxy/GNP nanocomposites in order to ensure machining accuracy in industrial production. Hence, the micro milling process is used to study the epoxy/GNP nanocomposites, for three reasons. Firstly, micro milling is an efficient and universal shaping and finishing process which has been applied in processing polymer/nanofiller composites [18, 19]. Secondly, micro milling can readily reveal the effect of particle content on nanocomposite performance, and thirdly, as a mechanical cutting process, micro milling will not influence the orientation of filler in the matrix material. Material performance can be directly used to guide the design and production of materials.

Micromachining has its own processing characteristics compared with macro machining due to the well-known size effect [20-22]. In micro milling of materials, when cutting is performed with a low FPT value, the chip is not always formed during each pass of the tool $[23,24]$. As the FPT decreases and its value approaches the cutting-edge radius of the tool, it becomes the most important factor in the transition state of shearing and ploughing. Instead, the material experiences severe ploughing/ friction during every pass of the tool $[25,26]$. The tool ploughs out the material, and the elastic recovery will dominate the material deformation, and no chips will be formed in each tool path [25-28]. When the uncut chip thickness is below a critical value, the size effect can have negative effect on the cutting process, such as higher cutting force, shorter tool life and worse dimensional surface quality [21, 29]. Hence, the ploughing area will directly affect the surface topography of the material and make the cutting force increase. Therefore, in order to understand the size effect of epoxy/GNP nanocomposites material, the size effect is studied in terms of surface morphology, cutting force and surface roughness.

Samuel et al. [18] conducted a study of the micromachining of polymer/carbon nanotube nanocomposites and investigated the cutting forces, tool wear, surface roughness and chip morphology. Dogrusadik and Kentli [30] had studied the micromachining behaviour of CFRP laminates. However, there is still very limited experimental data about the micromachining of epoxy/GNP nanocomposites. Hence, the machinability of epoxy/GNP nanocomposites will be investigated through the micro milling process. The experimental results can then be used to guide production and material design. Xu et al. [31] had investigated the machinability of CFRP composites using drilling method, and the studies provide good examples for this study.

The novelty of this research is to investigate the effect of graphene-derived nanofillers on the machinability of polymer materials. The GNP nanofiller is an important filler to improve the matrix material mechanical properties. For further industry applications, the effect of GNP nanofiller content on the machining behaviour should be understood. This paper is
Table 1 Mechanical properties, Young's modulus [37]

\begin{tabular}{llllll}
\hline Materials & $\begin{array}{l}\text { Plain } \\
\text { epoxy }\end{array}$ & $\begin{array}{l}\text { Epoxy/GNP } \\
0.1 \mathrm{wt} \%\end{array}$ & $\begin{array}{l}\text { Epoxy/GNP } \\
0.3 \mathrm{wt} \%\end{array}$ & $\begin{array}{l}\text { Epoxy/GNP } \\
0.5 \mathrm{wt} \%\end{array}$ & $\begin{array}{l}\text { Epoxy/GNP } \\
1.0 \mathrm{wt} \%\end{array}$ \\
\hline $\begin{array}{l}\text { Young's modulus } \\
(\mathrm{MPa})\end{array}$ & 600 & 750 & 740 & 720 & 705 \\
\hline
\end{tabular}




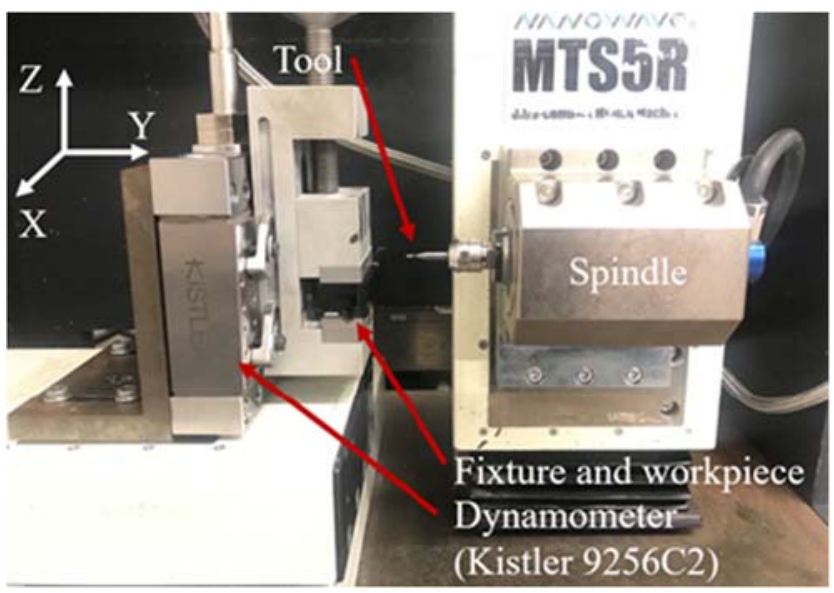

Fig. 4 Machine setup with cutting force dynamometer

organised as follows: Section 2 describes the preparation of the workpiece material, and the experimental set-up and procedure. Section 3 reports the results with a discussion of the size effect, slot width accuracy, surface morphology, cutting force, surface roughness and tool wear. Section 4 presents the conclusions drawn from the study.

\section{Experiments}

\subsection{Workpiece material preparation}

GNP was first dispersed in a hardener by bath sonication for $30 \mathrm{~min}$ at room temperature. The suspension was then mixed for 10 min with liquid epoxy resin at a ratio of resin to hardener of 2:1 and degassed under vacuum to remove entrained air. It was then moulded and cured at room temperature for $6 \mathrm{~h}$ and subsequently cured at $80^{\circ} \mathrm{C}$ for $6 \mathrm{~h}$ [21]. The samples that we get are epoxy/GNP $(0.1,0.3,0.5,1.0 \mathrm{wt} \%)$ nanocomposites. Figure 1 shows the samples used in the machining trials, including a scanning electron microscopy (SEM) image of GNP and GNP clusters and a transmission electron microscopy (TEM) image of layered GNP in epoxy matrix [33]. Figure 2 shows SEM images of fracture surfaces in epoxy/GNP and plain epoxy [32]. The presence of GNP filler causes significant
Table 2 Specifications of the uncoated micro-end milling tool

\begin{tabular}{ll}
\hline Properties & Value \\
\hline Tool diameter & $1 \mathrm{~mm}$ \\
Shank diameter & $3 \mathrm{~mm}$ \\
Number of flutes & 2 \\
Flute style & Right-hand spiral/medium helix \\
Finish/coating & Uncoated \\
Helix angle & $30^{\circ}$ \\
\hline
\end{tabular}

changes in the fracture surfaces of matrix materials. Figure 3 shows the samples used in the machining experiments.

The mechanical testing epoxy/GNP nanocomposites used in this study have been studied by several researchers. Mohd et al. [35] had been demonstrated that the addition of GNP nanofillers can increase the glass transition temperature of the matrix material. In the case of $0.7 \mathrm{wt} \%$ GNP nanofillers, the glass transition temperature increased from $80.85{ }^{\circ} \mathrm{C}$ to $87.59{ }^{\circ} \mathrm{C}$. Meanwhile, Ait et al. $[36,37]$ had been demonstrated that the GNP showed a maximum increase in hardness up to $18.3 \%$ compared with the plain epoxy. Meanwhile, the fracture surfaces of tensile specimens showed that the fracture mode was significantly altered by GNP nanofillers. Table 1 shows the effect of GNP content on the Young's modulus. The addition of GNP significantly increases the Young's modulus of the matrix materials.

\subsection{Experimental set-up}

Micro milling experimentation was carried out under dry conditions. The experiments were carried out on an ultraprecision desktop micromachine tools (MTS5R) with a continuous power of $100 \mathrm{~W}(240 \mathrm{~V})$ and $80,000 \mathrm{rpm}$ maximum spindle speed. The machine consists of 3 axes (X, Y, $\mathrm{Z}$ ) with $0.1 \mu \mathrm{m}$ resolution which is controlled by DC servo motors. The cutting forces were measured by using a Kistler cutting force dynamometer $(9256 \mathrm{C} 2)$, as shown in Fig. 4.
Fig. 5 Schematic diagram of the uncoated $1 \mathrm{~mm}$ diameter tool
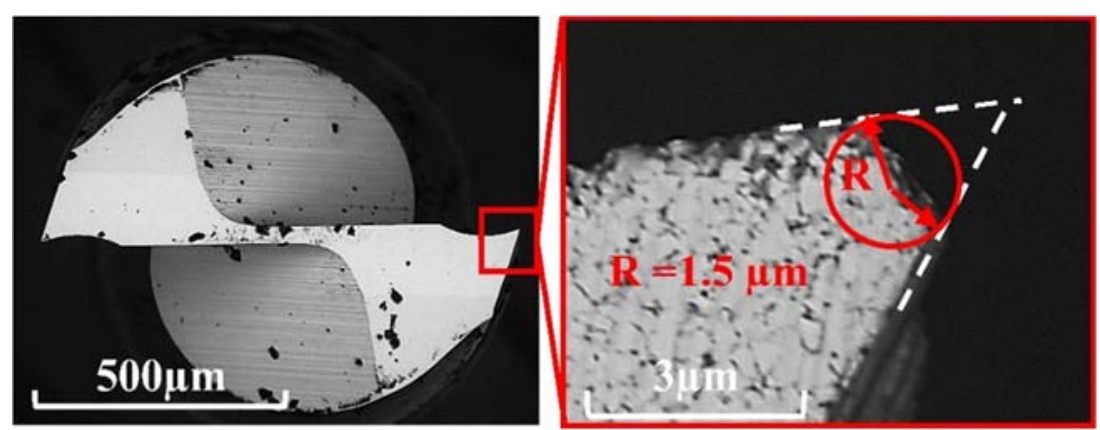


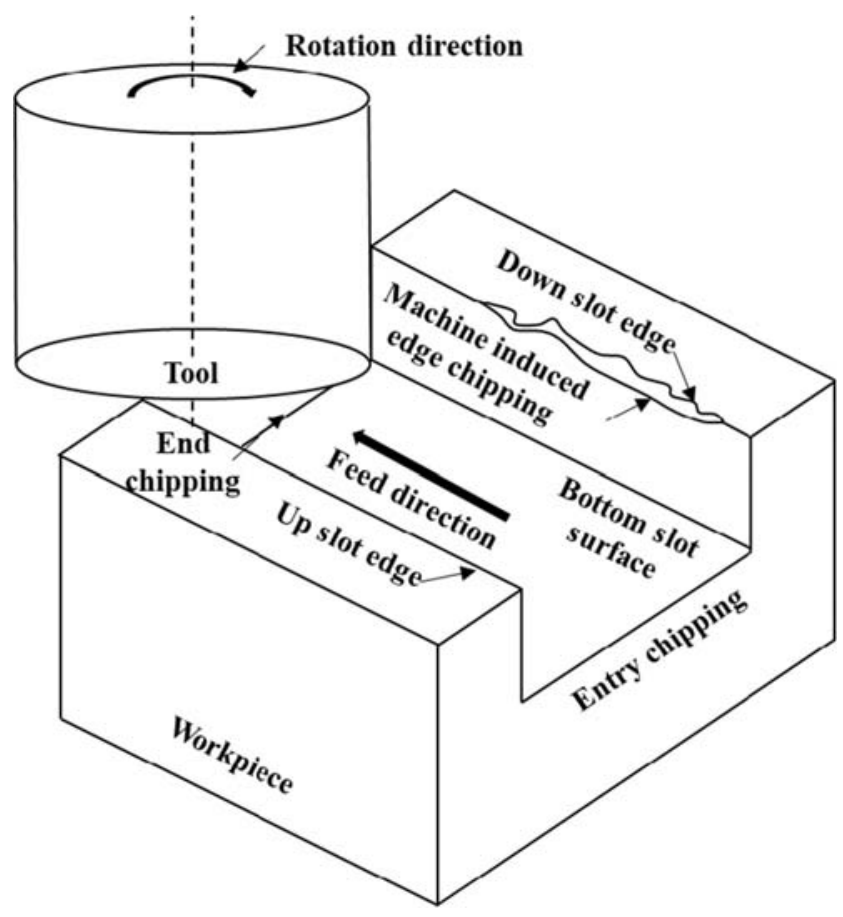

Fig. 6 Schematic of a machined slot with machining-induced edge

\subsection{Experimental procedure}

A $1 \mathrm{~mm}$ diameter uncoated end mill, a DLC (diamond-like carbon) coated tool and a diamond-coated tool were used in this study. Before the experiments, the tools were inspected using the SEM to ensure that the new tool was free from edge damage and chipping. Meanwhile, the radius of the cutting edges was measured. Figure 5 illustrates the cutting-edge radius of $1.5 \mu \mathrm{m}$, and Table 2 lists the specifications of the uncoated tool end mill.

Figure 6 shows a schematic of a machined slot with a machining-induced edge. Two sets of micro milling experiments were conducted to study the machinability of epoxy/ GNP nanocomposites. In order to ensure the accuracy of the experimental results, each set test was repeated twice. In this study, the depth of cut of all experiments was maintained at $0.1 \mathrm{~mm}$. Scanning electron microscopy (SEM) was used to check the surface quality and surface morphology. Tool flank wear data was also collected using SEM and measured with

Table 3 Cutting conditions for the first set experiment

\begin{tabular}{lclll}
\hline Cutting parameters & Level 1 & Level 2 & Level 3 & Level 4 \\
\hline Feed per tooth $(\mu \mathrm{m})$ & 5 & 10 & 15 & $/$ \\
Feed rate $(\mu \mathrm{m} /$ tooth) & 10 & 20 & 30 & $/$ \\
Cutting speed $(\mathrm{m} / \mathrm{min})$ & 15.7 & 31.4 & 62.8 & 94.2 \\
Spindle speed $(\mathrm{rpm})$ & 5000 & 10,000 & 20,000 & 30,000 \\
Depth of cut $(\mu \mathrm{m})$ & 100 & $/$ & $/$ & $/$ \\
\hline
\end{tabular}

ImageJ. The surface roughness (Ra) of the bottom slots was measured by using a Mitutoyo Surface SJ-410.

Experiments were conducted firstly to study the machinability properties of epoxy/GNP nanocomposites at 3 levels $(5,10$ and $15 \mu \mathrm{m} / \mathrm{rev})$ of feed per tooth and at 4 levels (15.7, $31.4,62.8$ and $94.2 \mathrm{~m} / \mathrm{min}$ ) of cutting speed, as shown in Table 3. Further experiments then studied the size effect and minimum chip thickness (MCT) of epoxy/GNP nanocomposites, and the milling conditions used are described in Table 4. Values of feed per tooth (FPT) ranged from $0.05 \mu \mathrm{m} /$ tooth to $6.0 \mu \mathrm{m} /$ tooth.

Tool wear is an important machinability measure that dictates the final cost of a machined part [38]. In order to quantify the effect of GNP loading on tool wear, a separate set of machining tests was conducted. In these tests, three types of $1 \mathrm{~mm}$ diameter end mills were used (uncoated tool, diamond-like carbon-coated tool and diamond-coated tool) to machine epoxy/GNP $0.3 \mathrm{wt} \%$ nanocomposites. Each tool was first characterised under a SEM microscope by observing its initial condition. Each run consisted of one hundred times and the removal of $130 \mathrm{~mm}^{3}$ volume. The total removal runs five times. The volume removed for every slot was $1.3 \mathrm{~mm}^{3}(1 \mathrm{~mm} \times 13 \mathrm{~mm} \times 0.1 \mathrm{~mm})$. The axial depthof-cut, FPT and cutting speed were maintained at $0.1 \mathrm{~mm}$, $5 \mu \mathrm{m}$ and $62.8 \mathrm{~m} / \mathrm{min}$, respectively, for the duration of each run, as shown in Table 5. At the end of each run, the tool tip was imaged on SEM to record the extent of tool wear. Meanwhile, Table 6 presents the specifications of the coated micro-end milling tools.

\section{Results and discussion}

\subsection{Surface roughness}

Figure 7 shows the surface roughness results from the micro milling of plain epoxy and epoxy/GNP nanocomposites at various values of feed per tooth. The surface roughness increased with the FPT increase, because the plain epoxy is a brittle material [39]. When cutting brittle materials, the chips are discontinuous chips. Due to this discontinuity, some pits are left on the machined surface. As the FPT increases, more and more pits are formed on the surface, gradually increasing the surface roughness. This phenomenon is consistent with the results of the previous machining experiments with plain polymer material [8].

Epoxy/GNP nanocomposites have higher surface roughness compared with plain epoxy. This may be due to two reasons. One is the toughening mechanism of GNP [9]. During the machining process of epoxy/GNP, a crack deflect is generated on the deformation area [9]. The tilting and twisting of the crack front as it is forced to move out of the initial propagation plane also forces the crack to grow locally under 
Table 4 Cutting conditions for the size effect experiment

\begin{tabular}{llll}
\hline $\begin{array}{l}\text { Feed per tooth } \\
(\mu \mathrm{m} / \text { tooth })\end{array}$ & $\begin{array}{l}\text { Cutting speed } \\
(\mathrm{m} / \mathrm{min})\end{array}$ & $\begin{array}{l}\text { Spindle } \\
\text { speed }(\mathrm{rpm})\end{array}$ & $\begin{array}{l}\text { Depth of } \\
\text { cut }(\mu \mathrm{m})\end{array}$ \\
\hline $\begin{array}{l}0.05,0.1,0.15, \\
0.2,0.3,0.4,\end{array}$ & 62.8 & 40,000 & 100 \\
$0.5,0.8,1.1$, & & & \\
$1.4,1.7,2.0$, & & \\
$3.0,4.0,5.0$, & & & \\
6.0 & & \\
\hline
\end{tabular}

mixed-mode (tensile/in-plane shear and tensile/anti-plane shear) conditions. Crack propagation under mixed-mode conditions is associated with higher driving force than in Mode I (tension) and higher fracture toughness of the material. Increased fracture toughness directly increases surface roughness [40]. Another reason for the higher surface roughness is that the glass transition, $T_{g}$, slightly increases with the GNP content increase [41].

Epoxy/GNP nanocomposites have higher surface roughness at low FPT values, as shown in Fig. 7. This is due to the toughening mechanism of GNP [9]. Due to the addition of GNP, the facture toughness increases. The tool ploughs out the material, and elastic recovery dominates the deformation of the material at low FPT values $\leq 1.0 \mu \mathrm{m}$ [34]. Hence, in order to achieve the better surface quality, as can be seen from Fig. 8 , the FPT value of epoxy/GNP should be over $2 \mu \mathrm{m}$.

\subsection{Surface morphology}

Figure 8 shows SEM images for the machined surface at various feed per tooth values (from 0.05 to $6.0 \mu \mathrm{m}$ ). There are many small cracks which appear on the surface of epoxy/GNP $0.1 \mathrm{wt} \%$ compared with plain epoxy. There are two reasons for this. First is that the presence of GNP changes the fracture mode. Atif et al. [37] has shown that the fracture mode changed significantly after adding GNP to the polymer. The fracture mode of plain epoxy is brittle fractures mode. The fracture mode of epoxy/GNP is nonlinear and parabolic fracture patterns mode. Second, a change in fracture mode causes the deformation process to change, which directly affects the surface morphology [42-44]. Rafiee et al. [10] have been demonstrated that the addition of $0.1 \mathrm{wt} \%$ GNP causes a significant increase in fracture toughness, as shown in Fig. 9. Anstis et al. [45] and Chantikul et al. [46] have shown that a

Table 5 Cutting conditions for the tool wear experiment

\begin{tabular}{llll}
\hline $\begin{array}{l}\text { Feed per tooth } \\
(\mu \mathrm{m} / \text { tooth })\end{array}$ & $\begin{array}{l}\text { Cutting speed } \\
(\mathrm{m} / \mathrm{min})\end{array}$ & $\begin{array}{l}\text { Spindle } \\
\text { speed }(\mathrm{rpm})\end{array}$ & $\begin{array}{l}\text { Depth of } \\
\text { cut }(\mu \mathrm{m})\end{array}$ \\
\hline 2 & 188.4 & 60,000 & 100 \\
\hline
\end{tabular}

Table 6 Specifications of the coated micro-end milling tools

\begin{tabular}{lll}
\hline Properties & $\begin{array}{l}\text { Diamond-like } \\
\text { carbon-coated tool }\end{array}$ & Diamond-coated tool \\
\hline Tool diameter & $1 \mathrm{~mm}$ & $1 \mathrm{~mm}$ \\
Number of flutes & 3 & 3 \\
Flute style & $\begin{array}{l}\text { Right-hand } \\
\text { spiral/medium helix }\end{array}$ & $\begin{array}{c}\text { Right-hand } \\
\text { spiral/medium helix }\end{array}$ \\
Finish/coating & Diamond-like carbon-coating & $\begin{array}{l}\text { Diamond coating } \\
3^{\circ}\end{array}$ \\
Helix angle & $30^{\circ}$ & $30^{\circ}$ \\
\hline
\end{tabular}

change in fracture toughness causes the shape of surface cracks to change.

Epoxy/GNP $1.0 \mathrm{wt} \%$ has fewer surface cracks compared with epoxy/GNP $0.1 \mathrm{wt} \%$, as shown in Fig. 8. There are two reasons for these differences in the surface. One is that fracture toughness is reduced when GNP content increases [10], as shown in Fig. 9. The reduction in fracture toughness leads to a change in the shape of surface cracks [45]. The other reason is that the regions of GNP agglomeration also cause changes in the shape of surface cracks. When the GNP content exceeds $0.3 \mathrm{wt} \%$, GNP agglomeration will happen in the matrix material. Arora et al. [29] observed microcracks/fragments which were caused by the tool feed at the GNP agglomeration regions. The microcracks around the GNP agglomeration regions caused changes to the cracks on the machined surface.

\subsection{Cutting forces}

Measurements of resultant cutting force and specific cutting energy are the two main method used in the analysis of the machinability of a material. The resultant cutting energy is directly generated by the relative motion of the cutting tool

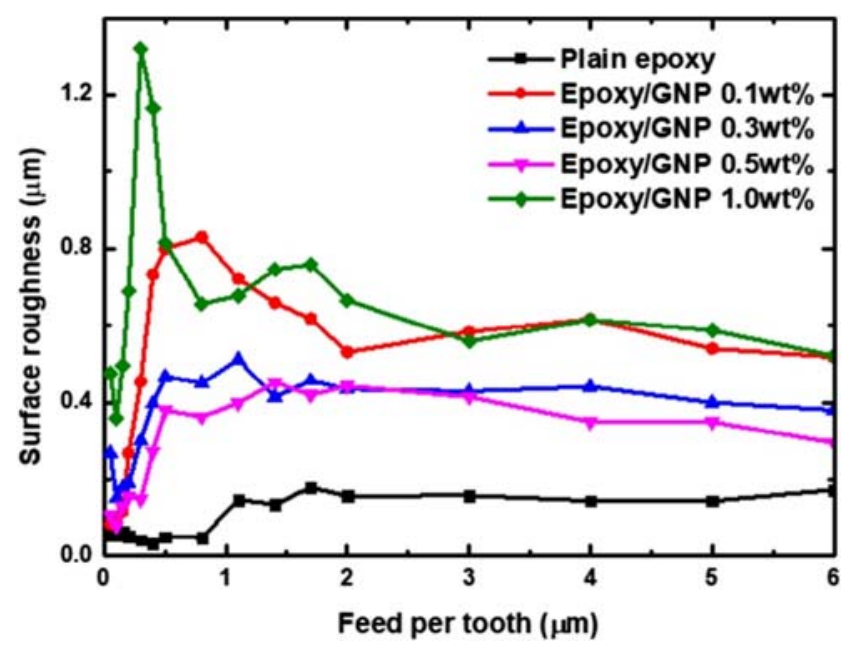

Fig. 7 Effect of FPT on surface roughness results 


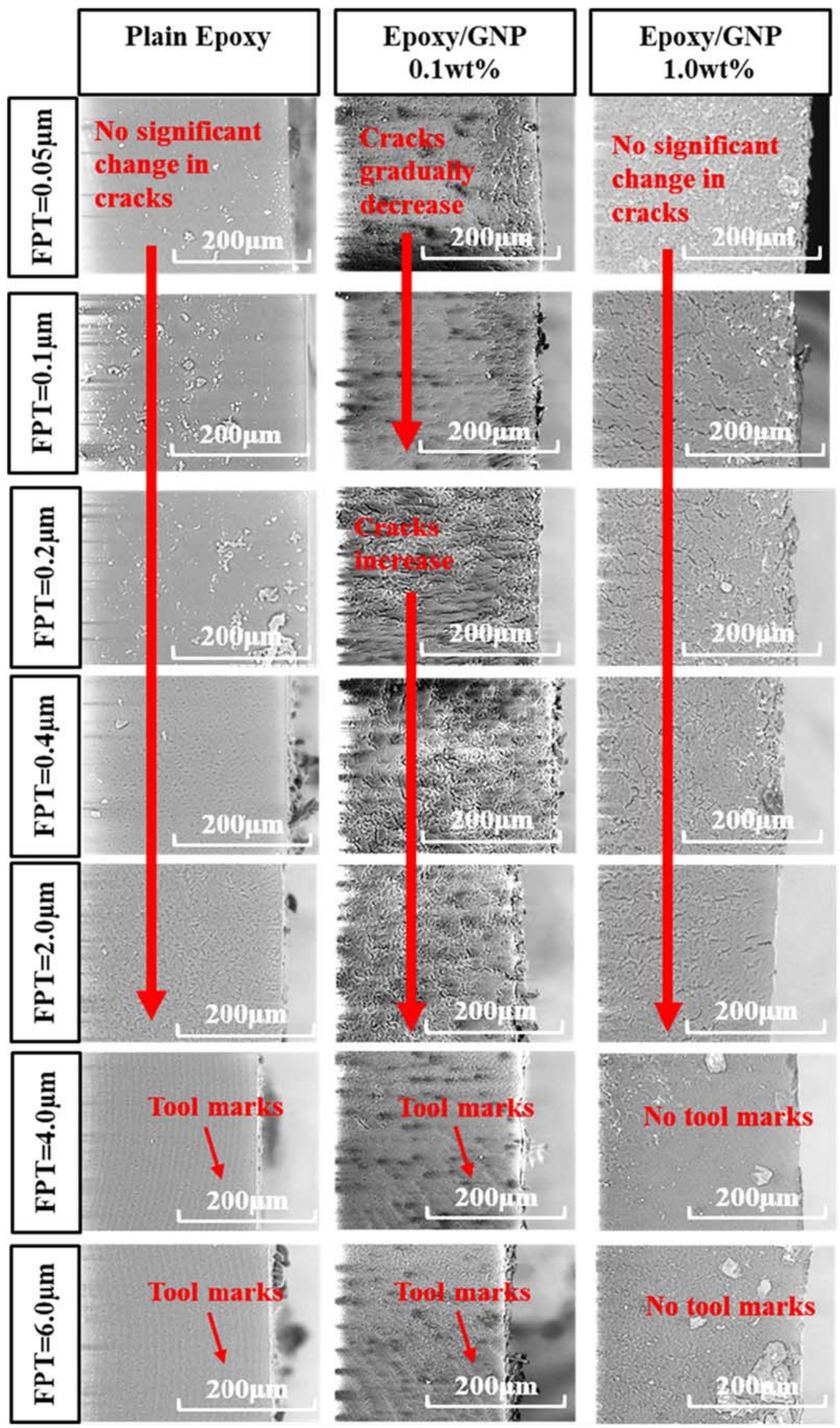

Fig. 8 SEM images of slot bottom surfaces for FPT values between 0.05 and $6.0 \mu \mathrm{m}$ 


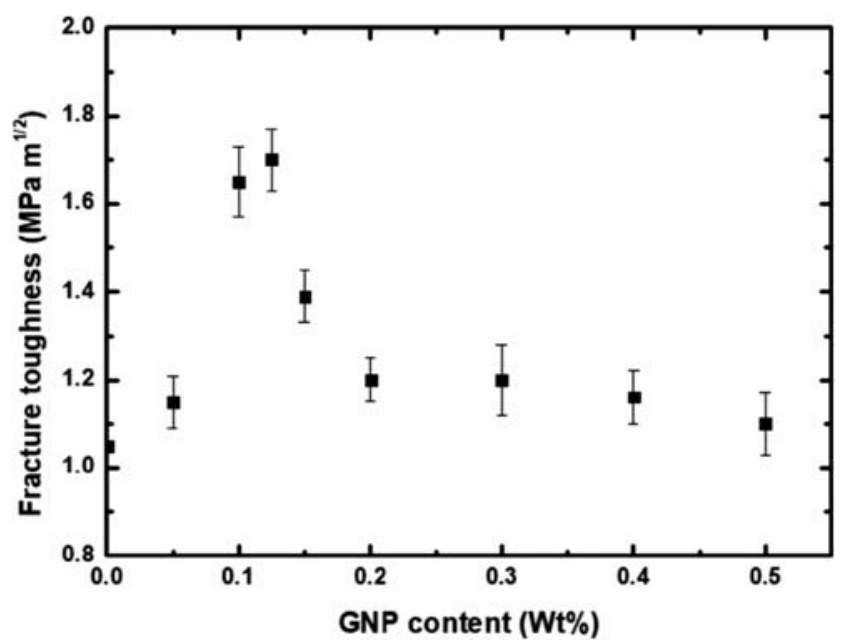

Fig. 9 Fracture toughness plotted as a function of GNP (wt $\%$ ) in the epoxy matrix [10]

with respect to the workpiece during machining. It occurs in the same direction as the movement of the cutting tool. Using the computed thrust force, $F_{t}$, and the cutting force, $F_{c}$, the specific cutting energy, F, is calculated using Eq. (1) [47].

$F=\sqrt{F_{t}^{2}+F_{c}^{2}}$

Figure 10 shows the resultant cutting force results of plain epoxy, epoxy/GNP $(0.1,0.3,0.5,1.0 \mathrm{wt} \%)$ nanocomposites at various values of feed per tooth. The cutting force trend for plain epoxy and epoxy/GNP nanocomposites is to first decrease and then rise with increasing FPT. The reduction in cutting force of the plain epoxy can be attributed to the face that plastic deformation and elastic deformation coexist in this region, and a small amount of recovery of the material will occur. The following region where the cutting force increases

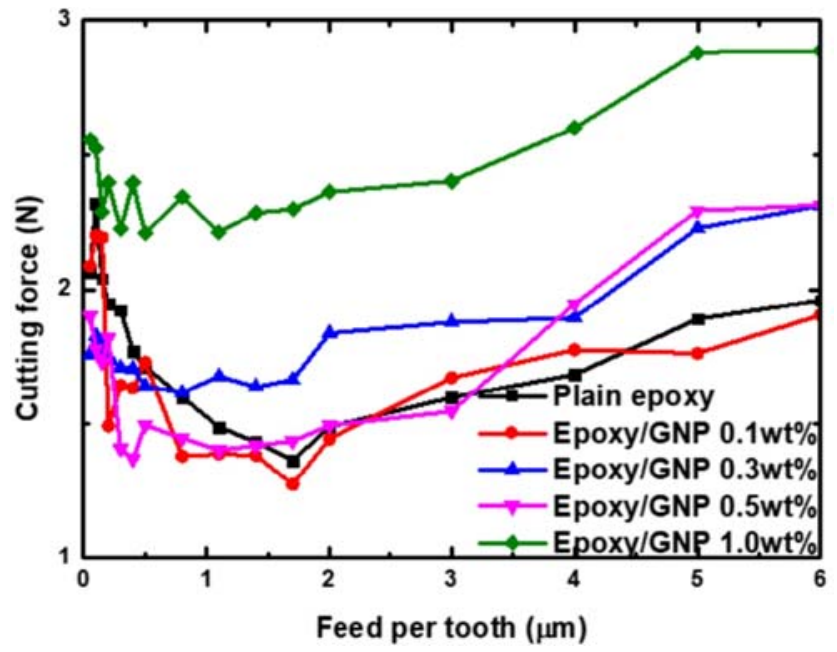

Fig. 10 Effect of GNP loading on cutting forces

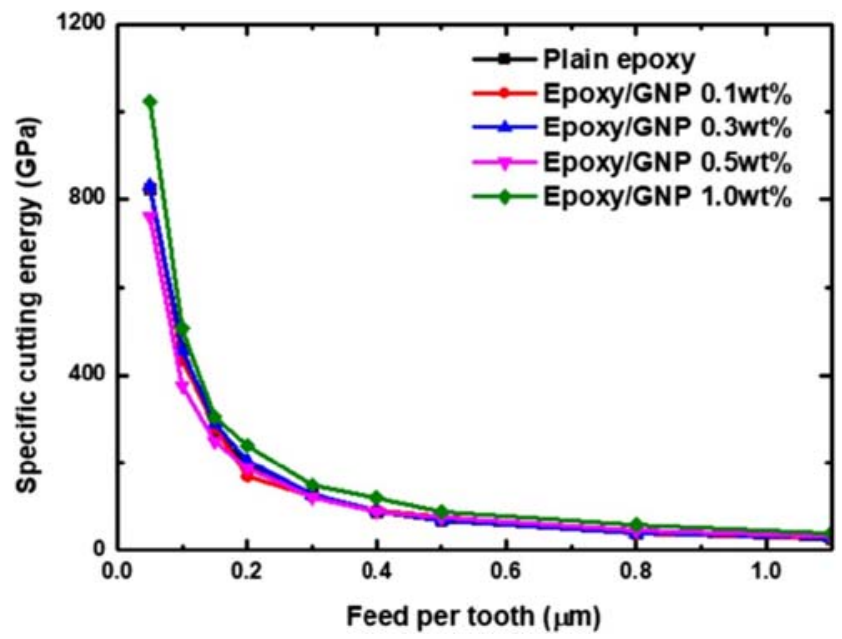

Fig. 11 Specific cutting energy results for epoxy/GNP in the second set of machining experiments

with feed per tooth can be ascribed to the fact that FPT is larger than MCT, which can produce continuous chips.

Figure 10 shows that the cutting force of epoxy/GNP is higher than that for plain epoxy. These may be the two reasons. One is that the crack deflection of epoxy/GNP absorbs more energy compared with plain epoxy. Crack deflection is the process by which an initial crack tilts and twists when it encounters a rigid inclusion. With the addition of GNP, more crack deflection occurs during the machining process. This generates an increase in the total fracture surface area, resulting in the absorption of more energy and greater cutting force compared with plain epoxy [10]. Secondly, the overall strength and modulus of the epoxy/GNP nanocomposites are greater, because the rough and wrinkled surface texture of graphene enhances the mechanical interlocking/adhesion with the polymer matrix $[8,48-50]$.

However, the cutting force of various epoxy/GNP $(0.1,0.3$ and $0.5 \mathrm{wt} \%$ ) nanocomposites are not very different. This may be because the GNP acts as a lubricant for the machining operation $[42,43]$, so that the friction between the tool edge and workpiece is reduced. This increase in lubrication properties may have cancelled out the effect of the increased overall strength and modulus of the epoxy/GNP nanocomposites. Another factor is that the presence of regions of GNP agglomeration means that the cutting force declines with increased GNP content [29]. The increase in cutting force is caused by overall strength and modulus. Again, the decrease in cutting force caused by GNP agglomeration may cancel out the effect of increased overall strength and modulus.

Specific cutting energy is the energy taken to remove a unit volume of the material, and this parameter can be used as an indicator in evaluating the size effect. Using the computed thrust force, $F_{t}$, and the cutting force, $F_{c}$, the specific cutting energy, $\mathrm{U}$, is calculated using the trapeze integration method shown in Eq. (2) [51]. 


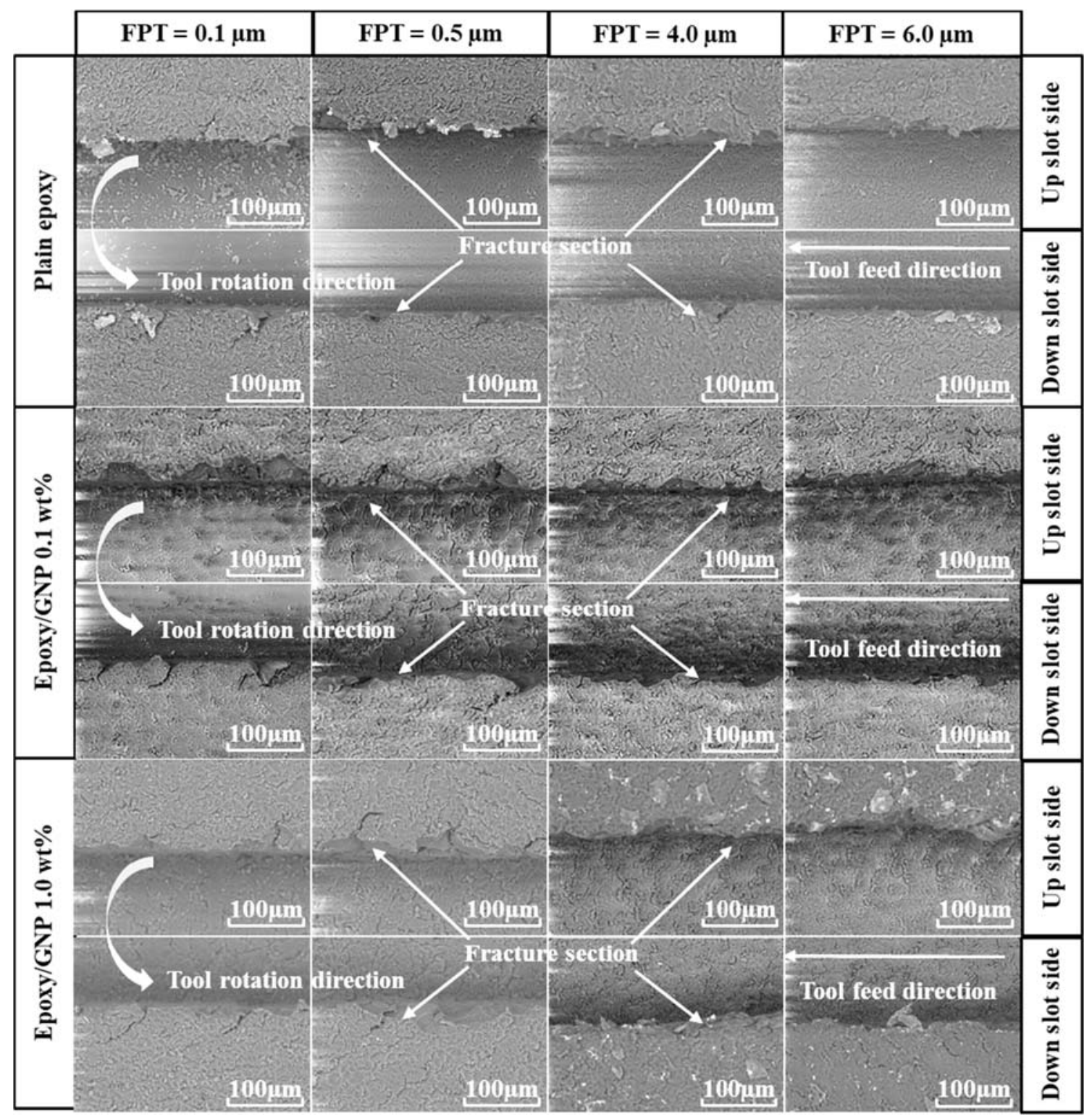

Fig. 12 SEM micrographs of micromachined slots for plain epoxy and epoxy/GNP nanocomposites

$U=\frac{V_{c}}{V_{r e m}} \times \int_{0}^{T_{c}} \sqrt{F_{t}^{2}+F_{c}^{2}} d t$

where $V_{c}$ and $V_{\text {rem }}$ are the cutting speed $(\mathrm{m} / \mathrm{min})$ and volume of material removal $\left(\mathrm{mm}^{3}\right)$, while $T_{c}$ is the cutting time (seconds). Figure 11 shows the specific cutting energy of various epoxy/GNP nanocomposites. As GNP is added, the specific cutting energy increases. Because the overall strength of the material rises, it takes more energy to remove the material per unit volume. The size effect can be observed according to the non-linear decrease of the specific cutting energy with feed per tooth. As illustrated in Fig. 11, as the ratio of FPT to the cutting-edge radius increases, the specific cutting energy decreases rapidly, and becomes stable at values of FPT between 0.2 and
$0.4 \mu \mathrm{m}$. Hence, the minimum chip thickness phenomena occur at FPT values between 0.2 and $0.4 \mu \mathrm{m}$.

Meanwhile, high specific cutting energy values produces high heat transfer rates and high residual stresses in the part, resulting in parts' poor surface integrity [52]. A low specific cutting energy means less damage to the machined surface and better surface quality and cutting tool efficiency [53]. Hence, surface roughness is low at values of FPT over $0.4 \mu \mathrm{m}$. This is consistent with the previously observed surface roughness values.

\subsection{Machined edge chipping and slot width accuracy}

Edge chipping is another critical factor in micromachining since it affects the capability to meet desirable tolerance and geometry criteria [40]. Thus, it is important to explore the edge 
Fig. 13 Images of the whole slot images from plain epoxy and epoxy/GNP nanocomposites

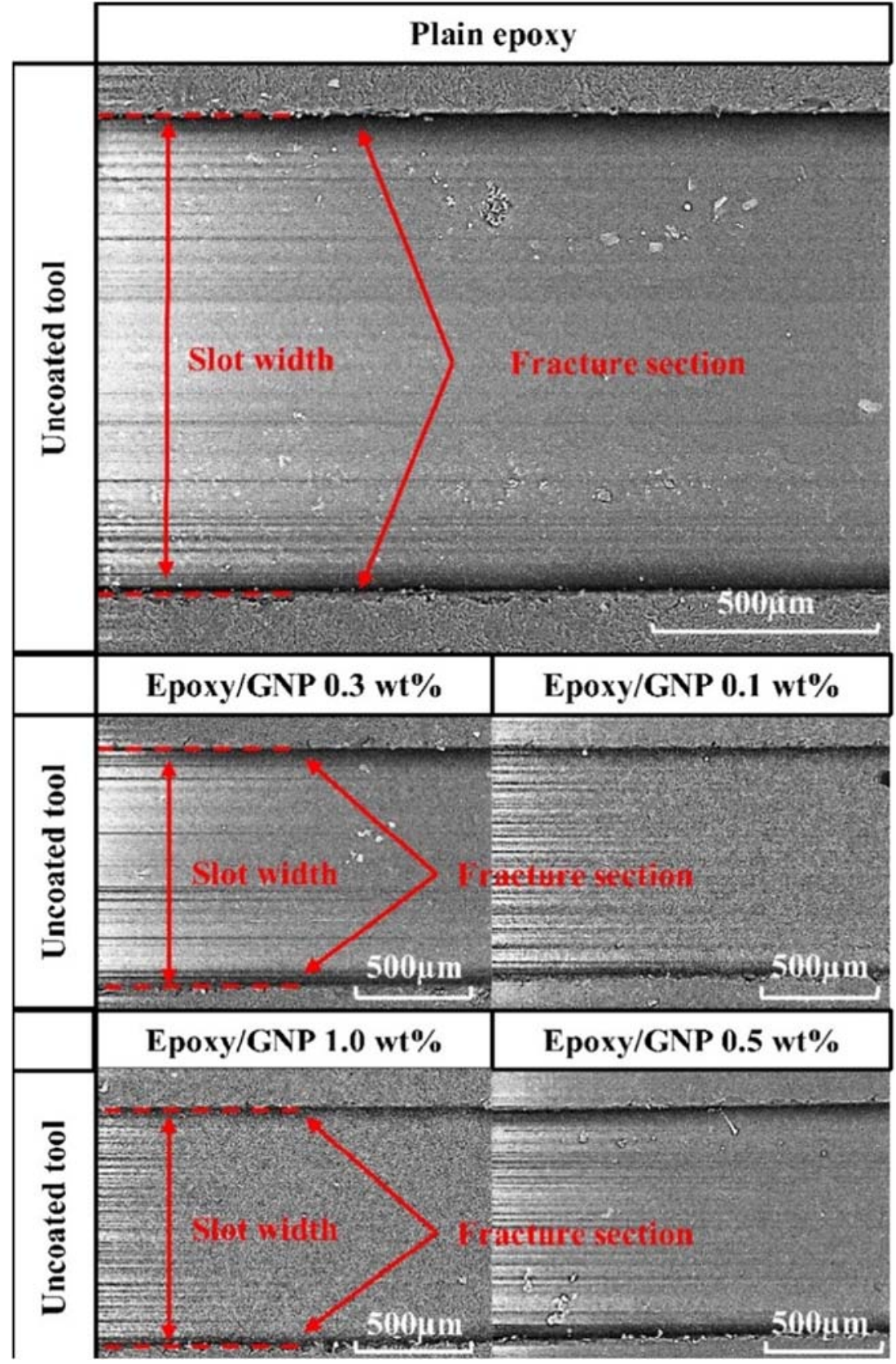

chipping either by developing strategies for its minimization or applying new post-processing technology for edge chipping $[29,46]$. Figure 12 shows up and down milling slot edges from the up and down milling of plain epoxy and epoxy/GNP (0.1 wt $\%$ and $1.0 \mathrm{wt} \%)$ nanocomposites at 4 levels of FPT $(0.1,0.5,4.0,6.0 \mu \mathrm{m})$. The epoxy/GNP shows significant differences in machined chipping compared with plain epoxy. There are many cracks in the slot edge of epoxy/GNP. This may be due to the addition of GNP nanofillers which significantly increase the fracture toughness [10]. The increase in fracture toughness causes the fracture mode to change [37].
The slot edge of plain epoxy exhibits burrs, and the epoxy/ GNP shows the edge chipping. Epoxy/GNP nanocomposites at $0.1 \mathrm{wt} \%$ exhibit smaller machined chipping breakage on the edge compared with those at $1.0 \mathrm{wt} \%$. This is mainly due to the increase in GNP content which leads to reduced fracture toughness [10], so that consequently, edge cracks are reduced.

Slot width can directly reflect the material's dimensional accuracy [8]. This study therefore investigates the effect of GNP content on slot width. Atif et al. [37] had been demonstrated that plain epoxy showed river-like markings that indicate the typical brittle fracture observed in epoxy. With the addition of GNP, a 


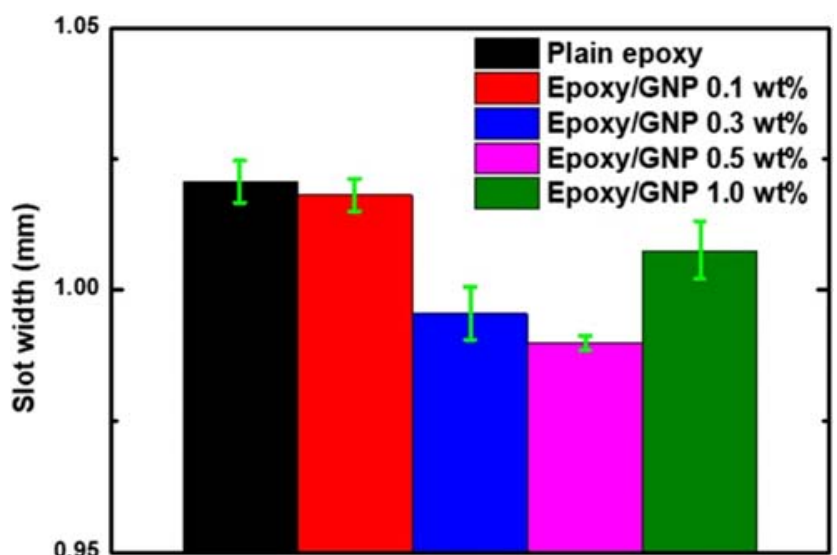

Fig. 14 Effect of GNP content on the slot width

rough dimple-like fracture surface was observed which shows that fracture mode had changed from brittle to ductile fracture. In this study, the effect of fracture mode changes in the machining process was examined. Figures 12 and 13 present SEM micrographs of micromachined slots for plain epoxy and epoxy/GNP nanocomposites. It is found that the slot edges of plain epoxy showed typical brittle fracture and lots of burrs. With the addition of GNP, the slot edge exhibited the chipping breakage mode. Hence, the addition of GNP directly changes the slot edge breakage mode. The addition of GNP directly changes the slot edge breakage mode from burring to chipping. All in all, the slot edge of epoxy/GNP under mixed-mode conditions during the machining process presents chipping formation, and plain epoxy under Mode I (tension) presents burr formation.

Figure 14 presents the slot width results against the volume of workpiece material removed. However, the addition of GNP nanofillers leads to a slightly decrease in slot width. There may be two reasons for this. One is that the addition of GNP nanofiller reduces the friction coefficient during the

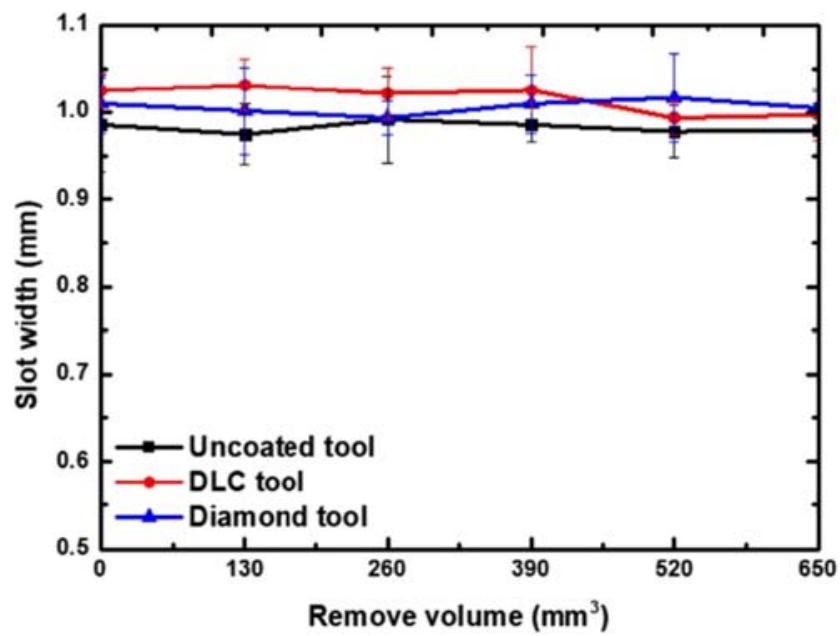

Fig. 15 Effect of tool life/material volume removed on slot width when machining epoxy/GNP $0.3 \mathrm{wt} \%$ nanocomposites

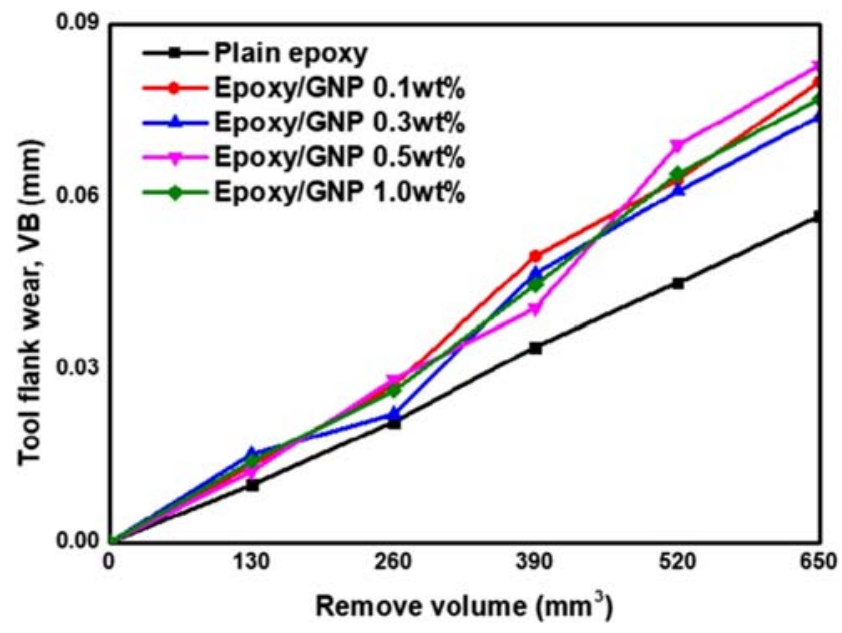

Fig. 16 Effect of GNP content on the tool flank wear

machining process. The reduced friction coefficient means that less friction heat is produced leads to less change in shape during machining. Another reason is that the addition of GNP nanofillers can increase the thermal conductivity of the matrix material $[54,55]$. Overall, the addition of GNP can improve the slot width accuracy. However, the effect of different ratios of the GNP content on the slot width cannot identify.

In order to provide more details for further industrial application, a set of experiment about the influence of tool types was designed. Figure 15 shows that only limited variations in slot width were observed regardless of the tool type and material removed until $650 \mathrm{~mm}^{3}$ volume had been removed. There is no significant difference in slot width accuracy between different types of tools. Hence, it is concluded that different tools cannot influence the slot width accuracy.

\subsection{Tool wear}

Figure 16 shows the effect of GNP content on the tool flank wear of the uncoated tool. The tool wear was quantified in terms of the distance between the two red lines, which was measured using a digital technique. With the addition of GNP, the tool wear of uncoated tools has a significantly increase. However, the effect of GNP content on the flank wear cannot identify. Meanwhile, in order to identify the tool wear mode, Fig. 17 shows SEM images of flank wear of uncoated tools for plain epoxy and epoxy/GNP $0.3 \mathrm{wt} \%$ nanocomposites. Uncoated tool suffered a progressive edge rounding, and the tool edges do not show the corner fracture.

Figure 18 shows that no significant flank wear of DLC and diamond tools can be observed until removing $650 \mathrm{~mm}^{3}$ volume of the workpiece material had been removed. DLC and diamondcoated tools experienced almost negligible wear compared with the uncoated counterpart. These coated tools suffered from chip adhesion on the flank face and coating delamination due to the consequence of machining stress. Meanwhile, the surface 
Fig. 17 SEM images of flank wear of uncoated tools for plain epoxy and epoxy/GNP $0.3 \mathrm{wt} \%$ nanocomposites
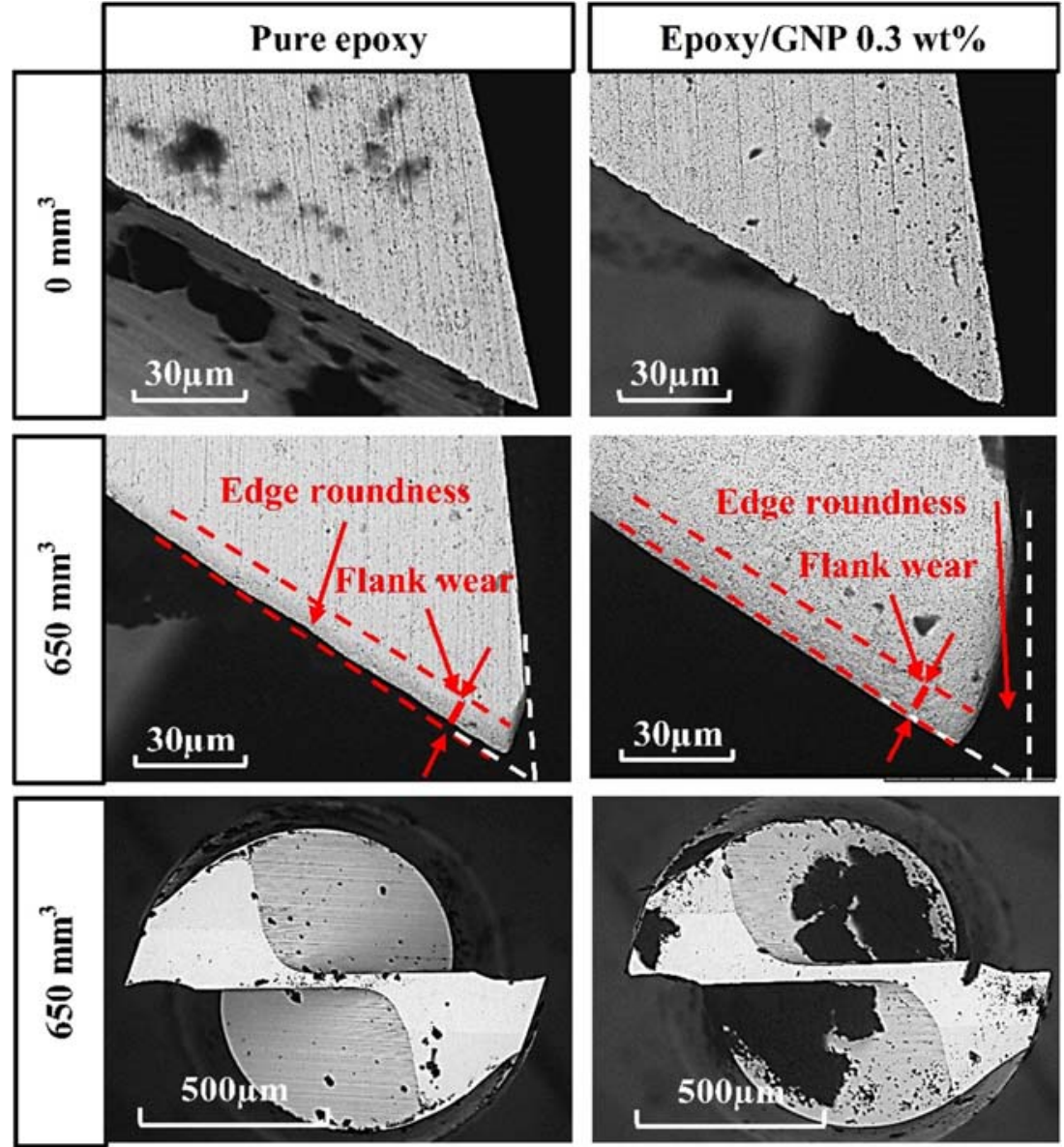

roughness of the machined by the uncoated tool was significantly influenced by the tool life, as shown in Fig. 19. From this figure, the surface roughness of nanocomposites machined by the uncoated tool increased linearly with the volume removed. The DLC tool and diamond tool do not show the breakage. There is only some coating delamination on these tools.

All in all, this section shows the correlation between the volumes of the workpiece material removed, with flank wear which was found to be directly related. However, the amount of tool wear when micromachining epoxy/GNP material is very small compared with its metallic nanocomposite counterparts [56].

\section{Conclusion}

The properties of epoxy/GNP nanocomposites were investigated by using a micromachining method. The effects and mechanisms of tool wear on reinforced materials were studied, and the cutting forces were analysed. In addition, nanocomposites surfaces were characterised in terms of surface morphology and surface roughness. Additionally, the size effect was studied, and the minimum cutting thickness was obtained based on the resultant cutting force and surface roughness. From this work, the following conclusions can be drawn:

- Epoxy/GNP nanocomposites present the different crack trends compared with plain epoxy. There are two reasons for this. Firstly, the presence of GNP changes the fracture mode, and secondly the increase in fracture toughness leads to changes in fracture mode from Mode I to mixed-mode. Due to the addition of GNP, nanofillers make the slot width slightly decreased, and GNP can slightly improve the shape accuracy.

- The minimum chip thickness phenomena for epoxy/GNP occurred at values of FPT between 0.2 and $0.4 \mu \mathrm{m}$. In order to achieve to better surface quality, the FPT should be over $0.4 \mu \mathrm{m}$ during the machining process.

- The tool wear of GNP/epoxy nanocomposites is very small compared with metal nanocomposites. When the tool has been used to cut $650 \mathrm{~mm}^{3}$ epoxy/GNP nanocomposites, the flank wear is $0.076 \mathrm{~mm}$. DLC (diamond-like carbon) tool and diamond tool exhibit no flank wear after removing $650 \mathrm{~mm}^{3}$ epoxy/GNP nanocomposites.

- The material with the highest cutting force was observed to be epoxy/GNP composite at $0.1 \mathrm{wt} \%$. This is attributed 

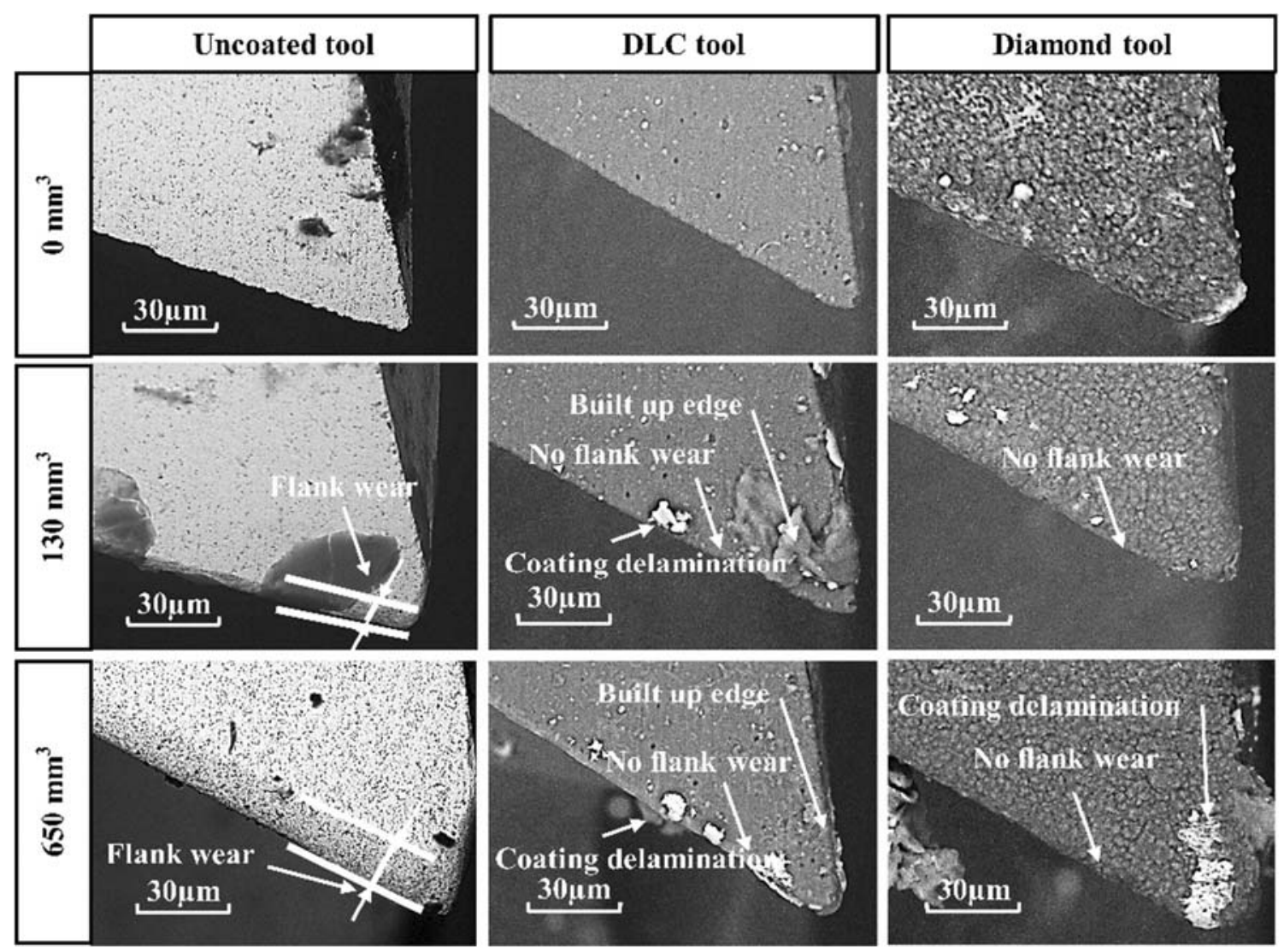

Fig. 18 SEM images of flank wear for three type tools

to its improved mechanical properties, such as improved tensile strength and improved Young's modulus.

- For industry application, the uncoated tool is fully qualified for machining the epoxy/GNP nanocomposites.

- The addition of GNP directly changes the slot edge breakage mode. It showed that breakage mode change from burr to chipping mode. Meanwhile, there is no relationship between the breakage mode of the slot edge and shape accuracy.

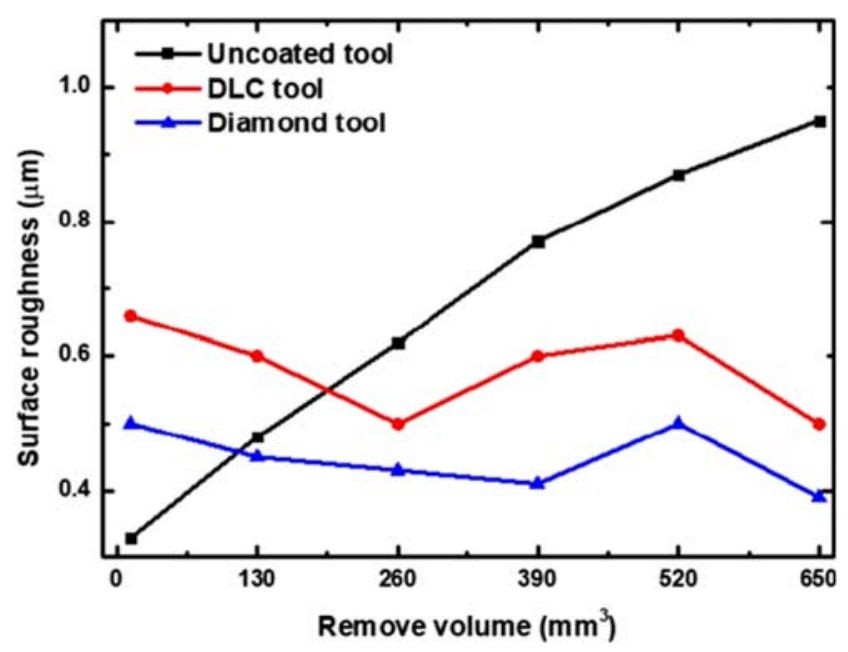

Fig. 19 Effect of tool life on surface roughness of epoxy/GNP $0.3 \mathrm{wt} \%$
- With the addition of GNP, the machining precision of the nanocomposites were not lowered. Moreover, nanocomposites have electrical and thermal conductivity and are of great help in the future of capacitors and capacitors.

Open Access This article is licensed under a Creative Commons Attribution 4.0 International License, which permits use, sharing, adaptation, distribution and reproduction in any medium or format, as long as you give appropriate credit to the original author(s) and the source, provide a link to the Creative Commons licence, and indicate if changes were made. The images or other third party material in this article are included in the article's Creative Commons licence, unless indicated otherwise in a credit line to the material. If material is not included in the article's Creative Commons licence and your intended use is not permitted by statutory regulation or exceeds the permitted use, you will need to obtain permission directly from the copyright holder. To view a copy of this licence, visit http://creativecommons.org/licenses/by/4.0/.

\section{References}

1. Singh V, Joung D, Zhai L, Das S, Khondaker SI, Seal S (2011) Graphene based materials: past, present and future. Prog Mater Sci 56(8):1178-1271

2. Zhu Y, Murali S, Cai W, Li X, Suk JW, Potts JR, Ruoff RS (2010) Graphene and graphene oxide: synthesis, properties, and applications. Adv Mater 22(35):3906-3924 
3. Potts JR, Dreyer DR, Bielawski CW, Ruoff RS (2011) Graphenebased polymer nanocomposites. Polymer 52(1):5-25

4. Van Noorden R (2011) Chemistry: the trials of new carbon. Nature 469(7328):14-16

5. Park S, Ruoff RS (2009) Chemical methods for the production of graphenes. Nat Nanotechnol 4(4):217

6. Lee C, Wei X, Kysar JW, Hone J (2008) Measurement of the elastic properties and intrinsic strength of monolayer graphene. Science 321(5887):385-388

7. Ramanathan T et al (2008) Functionalized graphene sheets for polymer nanocomposites. Nat Nanotechnol 3(6):327

8. Kumar MN, Mahmoodi M, TabkhPaz M, Park SS, Jin X (2017) Characterization and micro end milling of graphene nano platelet and carbon nanotube filled nanocomposites. J Mater Process Technol 249:96-107

9. Rafiee MA, Rafiee J, Yu ZZ, Koratkar N (2009) Buckling resistant graphene nanocomposites. Appl Phys Lett 95(22):223103

10. Rafiee MA et al (2010) Fracture and fatigue in graphene nanocomposites. Small 6(2):179-183

11. Gojny FH, Schulte K (2004) Functionalisation effect on the thermomechanical behaviour of multi-wall carbon nanotube/epoxy-composites. Compos Sci Technol 64(15):2303-2308

12. Shyha I et al. (2018) Micro-machining of nano-polymer composites reinforced with graphene and nano-clay fillers, in Key Engineering Materials, vol. 786, pp. 197-205

13. Bhattacharya M (2016) Polymer nanocomposites-a comparison between carbon nanotubes, graphene, and clay as nanofillers. Materials 9(4):262

14. López-Suárez M, Torres F, Mestres N, Rurali R, Abadal G (2014) Fabrication of highly regular suspended graphene nanoribbons through a one-step electron beam lithography process. Microelectron Eng 129:81-85

15. Han MY, Özyilmaz B, Zhang Y, Kim P (2007) Energy band-gap engineering of graphene nanoribbons. Phys Rev Lett 98(20): 206806

16. Novoselov KS et al (2005) Two-dimensional atomic crystals. Proc Natl Acad Sci 102(30):10451-10453

17. Berger $\mathrm{C}$ et al (2006) Electronic confinement and coherence in patterned epitaxial graphene. Science 312(5777):1191-1196

18. Samuel J, DeVor RE, Kapoor SG, Hsia KJ (2006) Experimental investigation of the machinability of polycarbonate reinforced with multiwalled carbon nanotubes. J Manuf Sci Eng 128(2):465

19. Blackman BRK et al (2007) The fracture and fatigue behaviour of nano-modified epoxy polymers. J Mater Sci 43(16):7049-7051

20. Cheng K and Huo D (2013) Micro-cutting: fundamentals and applications

21. Liu X, DeVor RE, Kapoor SG (2006) An analytical model for the prediction of minimum Chip thickness in micromachining. J Manuf Sci Eng 128(2):474-481

22. Du Kim J, Kim DS (1995) Theoretical analysis of micro-cutting characteristics in ultra-precision machining. J Mater Process Technol 47(3-4):387-398

23. Saito K (1981) Fracture phenomena of high polymers in cutting. J Macromol Sci Part B 19(3):459-485

24. Liu X, DeVor RE, Kapoor SG, Ehmann KF (2004) The mechanics of machining at the microscale: assessment of the current state of the science. J Manuf Sci Eng 126(4):666-678

25. Park SS, Malekian M (2009) Mechanistic modeling and accurate measurement of micro end milling forces. CIRP Ann - Manuf Technol 58(1):49-52

26. Korablev VN, Shcherbakov AK, Karpenko OL, Svistunova VP, and Svistunov VA, (1995) On the modeling and analysis of machining performance in micro-endmilling, part I: surface generation, Probl Tuberk, no. 1, pp. 52-53

27. Weule H, Hüntrup V, Tritschle H (2001) Micro-cutting of steel to meet new requirements in miniaturization. CIRP Ann 33(4):402-407
28. Aramcharoen A, Mativenga PT (2009) Size effect and tool geometry in micromilling of tool steel. Precis Eng 33(4):402-407

29. Arora I, Samuel J, Koratkar N (2013) Experimental investigation of the machinability of epoxy reinforced with graphene platelets. $\mathrm{J}$ Manuf Sci Eng 135(4):041007

30. Dogrusadik A, Kentli A (2019) Effect of support plates on the micro-drilled hole form quality in cfrp laminates. Mater Test 61(5):467-476

31. Xu J, Li C, Dang J, El Mansori M, Ren F (2018) A study on drilling high-strength CFRP laminates: frictional heat and cutting temperature. Materials (Basel) 11:1-18

32. Wei J (2017) Graphene in epoxy system: dispersion, preparation and reinforcement effect. Ph.D. dissertation, Dept. Eng., Northumbria University, Newcastle, Northumbria University

33. Saharudin M (2017) Mechanical properties of polyester nanocomposites exposed to liquid media. Ph.D. dissertation, Dept. Eng., Northumbria University, Newcastle, Newcastle

34. Teng CC et al (2011) Thermal conductivity and structure of noncovalent functionalized graphene/epoxy composites. Carbon 49(15):5107-5116

35. Saharudin M, Shyha I, and Inam F (2016) Viscoelastic and mechanical properties of multi-layered Graphene polyester composites

36. Atif R, Shyha I, Inam F (2016) Mechanical, thermal, and electrical properties of graphene-epoxy nanocomposites-a review. Polymers 8(8):281

37. Atif R, Wei J, Shyha I, Inam F (2016) Use of morphological features of carbonaceous materials for improved mechanical properties of epoxy nanocomposites. RSC Adv 6(2):1351-1359

38. Jaffery SI, Mativenga PT (2009) Assessment of the machinability of Ti-6Al-4V alloy using the wear map approach. Int J Adv Manuf Technol 40(7-8):687-696

39. Arola D, Ramulu M, Wang DH (1996) Chip formation in orthogonal trimming of graphite/epoxy composite. Compos Part A Appl Sci Manuf 27(2):121-133

40. Srivatsan TS (2009) A aeview of: ' fractography: observing, measuring, and interpreting fracture surface topography, D. Hull' , Mater. Manuf. Process., Cambridge University Press, Cambridge, UK, pp. 1229-1230

41. Domun $\mathrm{N}$ et al (2017) Improving the fracture toughness properties of epoxy using graphene nanoplatelets at low filler content. Nanocomposites 2(3):85-96

42. Carr JW, Feger C (1993) Ultraprecision machining of polymers. Precis Eng 15(4):221-237

43. Alauddin M, Choudhury IA, El Baradie MA, Hashmi MSJ (1995) Plastics and their machining: a review. J Mater Process Technol 54(1-4):40-46

44. König W, Wulf C, Graß P, Willerscheid H (1985) Machining of fibre reinforced plastics. CIRP Ann. - Manuf. Technol. 34(2):537548

45. ANSTIS GR, CHANTIKUL P, LAWN BR, MARSHALL DB (1981) A critical evaluation of indentation techniques for measuring fracture toughness: I, direct crack measurements. J Am Ceram Soc 64(9):533-538

46. CHANTIKUL P, ANSTIS GR, LAWN BR, MARSHALL DB (1981) A critical evaluation of indentation techniques for measuring fracture toughness: II, strength method. J Am Ceram Soc 64(9): 539-543

47. Altintaş Y, Budak E (1995) Analytical prediction of stability lobes in milling. CIRP Ann. - Manuf. Technol. 44(1):357-362

48. Atif R, Shyha I, Inam F (2017) Modeling and experimentation of multi-layered nanostructured graphene-epoxy nanocomposites for enhanced thermal and mechanical properties. J Compos Mater 51(2):209-220

49. Samuel J, Rafiee J, Dhiman P, Yu ZZ, Koratkar N (2011) Graphene colloidal suspensions as high performance semi-synthetic metalworking fluids. J Phys Chem C 115(8):3410-3415 
50. Marcon A, Melkote S, Kalaitzidou K, Debra D (2010) An experimental evaluation of graphite nanoplatelet based lubricant in micromilling. CIRP Ann. - Manuf. Technol. 59(1):141-144

51. Rodrigues AR, Coelho RT (2007) Influence of the tool edge geometry on specific cutting energy at high-speed cutting. J Braz Soc Mech Sci Eng 29(3):279-283

52. Salmon SC (1992) Modern grinding process technology

53. Ersoy A, Atici U (2004) Performance characteristics of circular diamond saws in cutting different types of rocks. Diam Relat Mater 13(1):22-37

54. Schaller T, Bohn L, Mayer J, Schubert K (1999) Microstructure grooves with a width of less than $50 \mu \mathrm{m}$ cut with ground hard metal micro end mills. Precis Eng 23(4):229-235
55. Liu S, Luo G, Wei F (2015) Poly(p-phenylene terephthalamide)/ carbon nanotube composite membrane: preparation via polyanion solution method and mechanical property enhancement. Compos Sci Technol 118:135-140

56. Filiz S, Conley CM, Wasserman MB, Ozdoganlar OB (2007) An experimental investigation of micro-machinability of copper 101 using tungsten carbide micro-endmills. Int J Mach Tools Manuf 47(7-8):1088-1100

Publisher's note Springer Nature remains neutral with regard to jurisdictional claims in published maps and institutional affiliations. 